\title{
Brain Plasticity and Disease: A Matter of Inhibition
}

\author{
Laura Baroncelli, ${ }^{1}$ Chiara Braschi, ${ }^{2}$ Maria Spolidoro, ${ }^{1}$ Tatjana Begenisic, ${ }^{3}$ \\ Lamberto Maffei, ${ }^{1,3}$ and Alessandro Sale ${ }^{1}$
}

${ }^{1}$ National Research Council (CNR), Neuroscience Institute, Via Moruzzi 1, I-56124 Pisa, Italy

${ }^{2}$ Department of Psychology, Florence University, Pizza San Marco 4, I-50121 Florence, Italy

${ }^{3}$ Laboratory of Neurobiology, Scuola Normale Superiore, Pizza Cavalieri 7, I-56126 Pisa, Italy

Correspondence should be addressed to Alessandro Sale, sale@in.cnr.it

Received 10 January 2011; Accepted 4 May 2011

Academic Editor: Graziella Di Cristo

Copyright ( 92011 Laura Baroncelli et al. This is an open access article distributed under the Creative Commons Attribution License, which permits unrestricted use, distribution, and reproduction in any medium, provided the original work is properly cited.

One major goal in Neuroscience is the development of strategies promoting neural plasticity in the adult central nervous system, when functional recovery from brain disease and injury is limited. New evidence has underscored a pivotal role for cortical inhibitory circuitries in regulating plasticity both during development and in adulthood. This paper summarizes recent findings showing that the inhibition-excitation balance controls adult brain plasticity and is at the core of the pathogenesis of neurodevelopmental disorders like autism, Down syndrome, and Rett syndrome.

\section{Introduction}

The term "plasticity" refers to the ability of the nervous system to reorganize its connections functionally and structurally in response to changes in environmental experience, underlying the adaptive development of neuronal circuitry. The existence of time windows in early postnatal life (critical periods) during which neural circuits display a heightened plasticity in response to external stimuli has been established for various brain regions subserving major behavioural functions (for review, see $[1,2]$ ). After the end of the critical period, neural plasticity dramatically wanes. Since the pioneering work by Wiesel and Hubel, the visual system stands as the prime model for studying experiencedependent plasticity. These authors reported that occluding one eye early in development (a treatment usually referred to as monocular deprivation) leads to an ocular dominance shift of cortical neurons, that is, a reduction in the number of cortical cells responding to that eye and a robust increment in the number of neurons activated by the open eye [3]. The imbalance of activity between the two eyes eventually results in the loss of synaptic inputs from the thalamic regions representing the closed eye and in the expansion of those driven by the open eye [4-7], accompanied by a remodelling of cortical horizontal connections [8].
In the last 50 years, great effort has been made to elucidate cellular and molecular mechanisms underlying the activation and regulation of critical periods in the brain. Unravelling these processes may potentially enable researchers to enhance plasticity in the adult brain. Moreover, a detailed knowledge of the events involved in the maturation and plasticity of neuronal circuitry would be a determinant in improving our understanding of the aetiology of developmental brain disorders.

Although a complete picture in the field is still lacking, a large body of evidence has been accumulated (see, $[9,10]$ ). In this paper, we will focus our discussion on intracortical inhibitory circuitry which convincingly emerges as a key factor not only for defining the boundaries of cortical plasticity but also in developing of pathological states characterized by severe intellectual disabilities (see also $[11,12]$ ).

\section{GABAergic Inhibition and Ocular Dominance Plasticity in the Adult Visual Cortex}

By sculpting the pattern and timing of neuronal electrical activity, inhibitory GABAergic circuits are an ideal candidate for regulating the processes of experience-dependent 
synaptic modifications. Taking advantage of gene-targeting technology, this hypothesis has been directly tested by abolishing the expression of the $65 \mathrm{kD}$ isoform of GABAsynthetic enzyme, hence reducing activity-dependent GABA synthesis and release at synaptic terminals. Mice that carry such a disruption of the GAD65 gene do not exhibit ocular dominance plasticity in response to monocular deprivation; only an enhancement of inhibition achieved with local delivery of diazepam enables a full rescue of ocular dominance plasticity in these mice [13].

Converging results obtained with different experimental approaches have subsequently confirmed the key role of GABAergic inhibition in brain development and plasticity (e.g., [14-17]). It is noteworthy that BDNF-overexpressing mice show an accelerated maturation of GABAergic cortical inhibition paralleled by a faster time course of critical period for ocular dominance plasticity [13], strongly suggesting that the progressive development of the inhibitory tone not only enables the onset of the critical period but subsequently underlies the closure of neural plasticity gates.

One of the major challenges in neuroscience is the development of strategies aimed at promoting nervous system plasticity in adulthood, when recovery from injury and functional rehabilitation are severely hampered. Recently, new evidence has challenged the classic dogma that ocular dominance plasticity is a physiological phenomenon exclusively restricted to the early postnatal development and pointed to a reduction of intracortical inhibition levels as a crucial step for the restoration of plasticity processes in the adult brain. The most direct demonstration that GABAergic inhibition limits plasticity in the adult visual cortex derives from a recent study reporting that pharmacological reduction of intracortical inhibition obtained through the infusion of either MPA (an inhibitor of GABA synthesis) or picrotoxin (a GABA $\mathrm{A}$ antagonist) directly into the visual cortex reactivates ocular dominance plasticity in response to monocular deprivation in adult rats [18]. Moreover, this treatment leads to a full rescue of long-term potentiation (LTP) of layer II-III field potentials induced by theta-burst stimulation from the white matter, an activitydependent form of synaptic plasticity which is normally occluded in visual cortical slices from adult animals due to the maturation of inhibitory transmission $[18,19]$. The reduction of intracortical inhibition is accompanied by processes of structural plasticity. The visual cortex of MPA or PTX-treated animals, indeed, shows a decrease in the density of chondroitin sulfate proteoglycans (CSPGs), indicating the activation of endogenous mechanisms of extracellular matrix remodelling which are known to be crucially involved in the expression of neural plasticity [20-22]. It is also possible that other molecular components of the extracellular milieu regulating synaptic plasticity in the adult brain, such as myelin proteins [23] and adhesion molecules [24], may undergo changes in their expression levels in response to a reduction of intracortical inhibition.

These results show that a brief reduction of GABAergic inhibition is sufficient to reopen a window of plasticity in the visual cortex well after the normal closure of the critical period. Similar conclusions have been drawn from recent evidence showing that the inhibitory tone is a central hub for the restoration of plasticity in the adult visual cortex and that a decrease of intracortical inhibition levels is required for the reinstatement of neural plasticity triggered by different experimental approaches. We demonstrated that environmental enrichment, a condition of increased sensorymotor and cognitive stimulation, reactivates juvenile-like ocular dominance plasticity in the visual cortex of adult rats, with a shift in ocular dominance of cortical neurons following monocular deprivation clearly detectable using both visual evoked potentials and single-unit recordings [25]. Recovery of plasticity in enriched animals is paralleled by a marked reduction of the inhibitory tone in the visual cortex. Importantly, the decrease of inhibitory neurotransmission is a crucial molecular mechanism underlying the enhancement of visual cortex plasticity induced by environmental enrichment: preventing the reduction of GABAergic inhibition during the period of exposure to environmental enrichment (via micro-osmotic pumps infusing the GABA agonist diazepam into the visual cortex), indeed, completely blocks the ocular dominance shift of cortical neurons in response to monocular deprivation [25]. The enhanced environmental stimulation provided by environmental enrichment also leads to a twofold enhancement of serotoninergic transmission and to an increase in the number of BDNF-expressing neurons in the visual cortex. Interestingly, infusion of a serotonin synthesis inhibitor not only blocks plasticity in response to monocular deprivation but also fully counteracts the effects produced by environmental enrichment on inhibition and BDNF levels. We suggested a model in which serotonin is the first trigger in the molecular chain set in motion by environmental enrichment, eliciting the decrease of GABA-mediated intracortical inhibition and, in parallel or in series, the enhancement of BDNF levels [25].

It is interesting to point out that while, during development, environmental enrichment increases BDNF and accelerates the maturation of inhibition in the visual cortex [15], in adult animals reared in an enriched environment increased levels of BDNF are associated with reduced GABAergic inhibition. One possible explanation for these apparently contrasting results is that the influence exerted by the environment on these molecular factors may follow a temporarily distinct sequence in the adult compared to the developing brain. Specifically, we propose that the very early (postnatal day 7, see [15]) increase in BDNF detected in mice reared from birth in an enriched environment may be the prime factor that directly drives the development of inhibitory circuitry in the immature brain; on the contrary, the enhancement of BDNF expression in animals exposed to environmental enrichment in adulthood may occur downstream to the decrease of intracortical inhibition, which could promote the expression of many activity-dependent genes involved in neural plasticity.

Given the central role of serotonin in promoting adult visual cortex plasticity, one might expect that the effects induced by environmental enrichment should be reproducible through an artificial modulation of cerebral levels of this neurotransmitter. This possibility has been addressed in a study by Maya Vetencourt et al. [26], showing 
that the administration of fluoxetine, a selective serotonin reuptake inhibitor (SSRI) widely prescribed in the treatment of depression for its capability to enhance extracellular serotonin levels, reinstates plasticity in the visual cortex of adult animals, with treated rats exhibiting a marked shift of ocular dominance in favour of the open eye after one week of monocular deprivation. Also in this case, a pronounced reduction of intracortical inhibition has been detected in the visual cortex, and the osmotic infusion of the GABA agonist diazepam fully prevents the ocular dominance shift induced by monocular deprivation, thus impeding plasticity in fluoxetine-treated animals. Further support to the notion that diffuse projecting systems of the brainstem affect plasticity in adulthood has been very recently provided by the demonstration that a genetic enhancement of nicotinic cholinergic transmission restores ocular dominance plasticity well after the end of the critical period. This effect is abolished by diazepam treatment, suggesting that the cholinergic signalling mechanisms may adjust excitatory-inhibitory balance [27].

Using an approach quite different from environmental enrichment, a study by $\mathrm{He}$ and colleagues reported that exposing adult animals to complete darkness can also promote plasticity in the visual cortex [28]. These authors provided indirect evidence that the enhanced cortical plasticity might be related to a shift in the balance between inhibition and excitation towards levels more similar to those found in the immature cortex, caused by a reduced expression of $\mathrm{GABA}_{\mathrm{A}}$ receptors relative to AMPA receptors. This suggestion has been confirmed in a very recent study [29] showing that dark exposure decreases inhibitory synaptic density and paired-pulse depression and reinstates in the visual cortex the expression of endocannabinoid-dependent inhibitory long-term depression, a form of synaptic plasticity normally restricted to the juvenile age [30].

Two different hypotheses, not mutually exclusive, could be formulated for explaining how the reduction of the inhibitory tone to juvenile-like levels leads to a recovery of cerebral plasticity in the adult brain. According to one hypothesis, the maturation of GABAergic intracortical transmission sets the point after which the editing activity of visual cortex pyramidal neurons enables ocular dominance plasticity; as development proceeds further, the inhibitory tone surpasses a threshold, and this causes the closure of the critical period. A reduction of inhibition levels may reinstate in the adult visual cortex the capability of binocular neurons to detect the imbalance in retinal inputs induced by the closure of one eye. According to an alternative hypothesis, the overall increase of cortical activity due to the shift in excitation-inhibition balance is the key factor favoring plasticity recovery. Activity-dependent regulation of gene expression could induce a genetic transcriptional program critical for promoting plasticity.

\section{Beyond the Visual Cortex}

The critical role of GABAergic inhibition in regulating experience-dependent plasticity is not restricted to the visual cortex.
In the barn owl, the optic tectum contains a map of space consisting of bimodal neurons whose auditory and visual receptive fields are mutually aligned. In juvenile owls, alternative maps of interaural time difference can be acquired as a result of abnormal experience. The group of Knudsen and colleagues has demonstrated the existence of a sensitive period for plasticity in the optic tectum by exposing owls at different ages to prismatic spectacles that cause a large horizontal shift of the visual field [31]. Owls bearing these spectacles experience a modification of the visual locations to which the interaural time difference values correspond, eliciting the adjustment of auditory receptive fields according to the optical displacement [31, 32]. Very interestingly, the environmental rearing conditions can have a dramatic impact on this form of plasticity. Indeed, the period during which owls respond adaptively to prismatic displacement of the visual field ends at about 70 days of age when owls are housed in individual cages, while it does not end until 200 days of age when owls are housed in groups and in larger enriched rooms [31]. At the same manner, also the ability to recover after restoration of normal visual experience is strongly affected by the environment, because it ends at 200 days of age when prism-reared owls are housed in small cages but extends throughout life when they are housed in group flight rooms. Soon after the characterization of the sensitive period for visual calibration of the auditory space map, Zheng and Knudsen demonstrated that when a new learned map is expressed in the external nucleus of the owl optic tectum, the neural circuitry underlying the old map is not structurally inactivated but becomes silent due to a functional suppression operated by inhibitory connections and involving GABAA receptors [33].

In the mammalian auditory system, a well-defined critical period exists for tone-specific enlargement in the primary auditory cortex (A1) representation resulting from transient exposure to sound stimuli [34]. Strikingly, the Merzenich's group has recently demonstrated that while in adult control rats this exposure produces no measurable alteration of A1 tonotopy, rats transferred to an environment of continuous moderate-level noise exhibit a re-establishment of a period of sound exposure-driven plasticity [35]. This effect, which is reminiscent of the reopening of critical period plasticity triggered in the visual system by dark exposure, is paralleled by a decrease in the expression level of GABAA $\alpha 1$ and $\beta 2 / 3$ subunits in A1.

Thus, reduction of GABAergic inhibition may emerge as a common feature of the strategies that successfully reopen a period of stimulus exposure-based plasticity in the adult brain $[18,25,26,28,35]$.

\section{Pathological Inhibition of Cerebral Function: The Case of Amblyopia}

During the critical period, the high susceptibility of neuronal connections to experience-dependent changes is essential for a proper maturation of normal sensory functions. This high potential for plasticity, however, may also favour the emergence of developmental pathological states when an 
anomalous perturbation of sensory-driven activity takes place. A paradigmatic case is that of amblyopia, a widely diffused and still untreatable pathology of the visual system affecting $2-4 \%$ of the total world population [36]. Amblyopia derives from conditions of early abnormal visual experience in which a functional imbalance between the two eyes is predominant owing to anisometropia (unequal refractive power in the two eyes), strabismus (abnormal alignment of one or both eyes), or congenital cataract, resulting in a dramatic loss of visual acuity and a broad range of other perceptual abnormalities, including deficits in stereopsis and contrast sensitivity $[37,38]$. It is worth stressing that in amblyopic patients the visual impairment is caused by an abnormal processing of visual information at the central level; thus, the use of corrective lenses is completely ineffective [39-41].

It is currently accepted that, due to a lack of sufficient residual plasticity within the brain, the reinstatement of visual functions in amblyopic subjects is possible only if corrective treatment is started early in development. The classic amblyopia therapy consists in patching or penalizing the preferred eye, thus forcing the brain to use the visual input carried by the weaker amblyopic eye [42]. However, an increasing number of clinical and animal studies are now challenging these traditional beliefs, reporting that repetitive visual training based on sensory enrichment procedures may represent a very useful approach for the treatment of amblyopia (for a comprehensive review, see $[38,43]$ ).

The mechanisms underlying vision improvements in adult amblyopic patients remain to be elucidated, since the activation of cortical plasticity may occur at several different levels of the visual system and through a variety of neural processes. A number of studies, however, suggested that an impairment of the balance between excitation and inhibition could affect visual cortex development and that cortical overinhibition could underlie the degradation of spatial vision abilities [44-48]. Accordingly, recent advances in our understanding of the cellular and molecular brakes that limit amblyopia recovery to a critical period underscored intracortical inhibition as a main obstacle for reinstatement of normal visual functions after a period of early abnormal visual experience. In animal models, amblyopia can be induced by imposing a long-term reduction of inputs from one eye by lid suture (i.e., with a protocol of longterm monocular deprivation). Similarly to that observed in humans, animals rendered amblyopic by long-term monocular deprivation display a permanent loss of visual acuity in the affected eye and a pronounced ocular dominance shift of visual cortical neurons in favour of the normal eye (e.g., [4951]).

Early studies in animal models of amblyopia reported that the administration of anti-inhibitory compounds (e.g., bicuculline) leads to a substantial restoration of binocularity in the visual cortex $[52,53]$. Recently, it has been shown that the same experimental paradigms discussed in Section 2 and associated with a reduced inhibition-excitation balance in the adult cerebral cortex are also able to recover sight from amblyopia (for review $[54,55]$ ). Among these treatments, environmental enrichment emerges as a totally non-invasive approach [56]. We reported that a brief exposure (twothree weeks) of adult amblyopic rats to environmental enrichment promotes a complete recovery of both visual acuity and ocular dominance, as demonstrated both with electrophysiological recordings of visual evoked potentials from the primary visual cortex and with a standard visual acuity behavioural test (visual water-box task). The environmental enrichment-induced recovery of visual acuity is long-lasting, persisting for a minimum of two weeks [56]. A reduced intracortical inhibition is a crucial mechanism underlying the enhancement of visual cortex plasticity in environmental enrichment: preventing the reduction of GABAergic inhibition during the period of environmental enrichment, indeed, completely blocks the recovery of binocularity and visual acuity. These findings draw attention to the environmental enrichment procedure as a prospective, injury-free, intervention strategy for amblyopia and further substantiate a major role for GABAergic transmission in the control of plasticity windows in the sensory cortices.

\section{Inhibition and Neurodevelopmental Disorders}

While the physiological maturation of GABAergic connections is essential for a tight control of developmental cortical plasticity and for promoting the acquisition of mature sensory abilities, it is currently accepted that abnormal levels of inhibition achieved during development can cause pathological states of severe brain disability $[11,57,58]$. On this regard, Rett syndrome, Down syndrome, and autism disorder stand as the most informative cases (the role of inhibition in schizophrenia is discussed in another review published in this issue).

5.1. Rett Syndrome. Rett syndrome is a progressive developmental disorder characterised by mental retardation and severe dysfunction in motor coordination skills [59], predominantly affecting the female population in early childhood. Using a systematic gene screening approach, lossof-function mutations in the X-linked gene encoding the methyl-CpG binding protein $(\mathrm{MeCP} 2)$ have been identified as the cause of Rett syndrome [60]. MeCP2 is involved in the regulation of expression of a wide range of genes [61] and in RNA splicing [62]. Transgenic mice carrying conditional deletion or neuron specific expression of mutated MeCP2 forms exhibit abnormalities in motor coordination, social interaction, and cognitive abilities, providing a useful model for analysing the behavioural and molecular phenotype of the Rett syndrome [63-66].

Detailed electrophysiological analysis of these animal models showed a reduction of neuronal activity in cortical and hippocampal neurons due to a shift in the balance between cortical excitation and inhibition in favour of inhibition $[67,68]$ and an attenuation of LTP expression in the hippocampus and in the motor and somatosensory cortex $[68,69]$. These results led to the hypothesis that an anomalous increase in the inhibition/excitation ratio could be responsible for the motor, behavioural, and cognitive defects associated with Rett syndrome [11]. This interpretation 
is supported by autoradiographic labelling studies on human postmortem brain samples, showing a significant increase in the density of GABA receptors that may correlates with cognitive and motor symptoms of Rett syndrome [70]. A very recent work by Chao and colleagues further demonstrated that a dysregulation of GABAergic system has a role in modulating the pathogenesis of Rett syndrome: mice lacking MeCP2 selectively in GABA-releasing neurons, indeed, recapitulate most of the behavioural features of Rett syndrome [71]. Surprisingly, these mice display a reduced inhibitory tone, while no data were presented concerning levels of excitation. Therefore, while these results confirm that a dysfunction of GABAergic neurons can contribute to the Rett phenotype, they also outline a more complex framework for the involvement of inhibitory transmission in Rett syndrome.

Since the gene encoding BDNF is under MeCP2 regulation [72] and the severity of behavioural symptoms in $\mathrm{MeCP} 2$ deficient mice correlate with levels of circulating BDNF [73], attempts have been made to rescue the Rett syndrome phenotype by delivering BDNF. It has been shown that exogenous BDNF in MeCP2 mutant mice is able to compensate for deficits at the behavioural, anatomical, and electrophysiological level [73, 74]. Pre-weaning environmental enrichment, which results in augmented cerebral BDNF levels, ameliorates motor and cognitive impairment and reverses cortical LTP deficits [75]. Very interestingly, environmental enrichment increases the number of cortical excitatory synapses with no changes found in inhibitory synaptic density, thus resulting in overall reduction of the cortical inhibitory tone [75].

5.2. Down Syndrome. Down syndrome is caused by triplication of chromosome 21 (Chr21) and is the most common genetic cause of mental retardation [76]. People with Down syndrome have moderate to severe cognitive impairment, with various disturbances in learning and memory abilities $[77,78]$. In search of possible molecular and cellular processes involved in the pathogenesis of the syndrome, several murine models have been generated, carrying triplications of different segments of Chr16, which has a large degree of synteny with human Chr21 [79, 80]. Currently, the prime model is the Ts65Dn transgenic mouse $[81,82]$, which recapitulates all main hallmarks of the Down syndrome phenotype, including characteristic craniofacial abnormalities, impaired spatial and nonspatial learning abilities, and attention and visual function deficits (e.g., [8385]). Anatomical studies indicated that Ts65Dn mice have a reduced number of cerebellar and hippocampal neurons [86-88], impaired neurogenesis in the dentate gyrus of the hippocampus (see [86, 89]; see also [90] for similar evidence in human foetuses), and simplified dendritic branching in several brain regions, associated with alterations in spine size and shape [91-93]. Moreover, dysfunctions in the mechanisms driving nerve-growth factor (NGF) retrograde transport from the hippocampus to the basal forebrain $[94,95]$ are responsible for a prominent degeneration of basal forebrain cholinergic neurons in adult Ts65Dn mice [96], which is also a hallmark of the Alzheimer's disease.
Accordingly, nearly one hundred per cent of persons born with Down syndrome develop Alzheimer's disease if they live into their fourth decade of life $[96,97]$.

A large number of studies have shown that the cognitive impairment displayed by Ts65Dn mice is mainly related to excessive levels of inhibition in temporal lobe circuitry, causing a failure of long-term synaptic plasticity in the hippocampus [98-100]. The deficit of synaptic plasticity is linked to marked morphological changes in the structure of synapses, with a selective enlargement of the active zones of symmetric synapses and increased immunostaining for synaptic proteins localized at inhibitory synapses in cortex and hippocampus $[101,102]$. The central role of overinhibition in Down syndrome pathogenesis has been recently confirmed by the demonstration that administration of noncompetitive antagonists of GABAA receptors reverses spatial learning disabilities and LTP deficits in Ts65Dn mice [100].

One of the major challenging tasks in the field of Down syndrome therapy is unravelling dosage-sensitive genes whose dysfunction, due to the presence of an extra copy of chromosome 21 , might be responsible for the main functional and morphological defects. A recent study by Chakrabarti et al. [103] has shown that two genes, Olig1 and Olig2, are essentially involved in the syndrome. The authors first reported that, very early in development, Ts65Dn mice have a marked increase in the number of forebrain GABAergic neurons generated in the medial ganglionic eminence (one of two regions in the ventral telencephalon where most inhibitory neurons proliferate and differentiate). More specifically, an overproduction of two specific classes of inhibitory neurons (i.e., parvalbumin- and somatostatinpositive neurons) has been detected. This anatomical phenotype is directly related to increased levels of inhibitory transmission in the forebrain of Ts65Dn mice, as assessed with electrophysiological methods [103]. Remarkably, a genetic reinstatement of dysomia at the level of Olig1 and Olig2 genes (obtained by breeding Ts65Dn mice with a line having only one copy of each of these genes) was sufficient to rescue the Ts65Dn phenotype, correcting the interneuron overproduction and restoring synaptic transmission to euploid levels [103]. Even if a behavioural assessment of the cognitive performance in Ts65Dn mice after reestablishment of dysomia was not reported, these results suggest that a few dosage-sensitive genes might eventually be responsible for many of the deficits displayed by people with Down syndrome and further support a causal link between aberrant inhibition in cortical and hippocampal circuitries and cognitive impairment due to Down syndrome.

Despite the increasing knowledge concerning the molecular mechanisms underlying Down syndrome, a suitable treatment for this disorder is still lacking. Since environmental enrichment is particularly effective in reducing GABAergic inhibition [104], it may have a great potential for therapeutic application to Down syndrome. MartínezCué et al. have reported increased exploratory behaviour and enhanced spatial learning in enriched Ts65Dn mice, albeit the effect was gender-specific [105]. Despite these results, a detailed investigation of the environmental enrichment effects on Down syndrome pathogenesis is still lacking. 
5.3. Autism. Autism is a heterogeneous developmental disorder characterised by significant impairments in the social, communicative, and cognitive domain and by the presence of repetitive patterns of stereotyped activities [106, 107], mostly affecting males in early childhood [108]. The advent of magnetic resonance imaging enabled the in vivo investigation of structural brain morphology in people with autism. Several regions have been reported to be enlarged or reduced relative to controls, but a large consensus on these results is currently missing (for a review, [109]).

The aetiological mechanisms of autism are at present poorly defined. Despite a likely contribution of environmental causes, genes play a crucial role in the onset of this pathology with concordance between monozygotic twins reaching $90 \%$, as compared with less than $10 \%$ for dizygotic twins and siblings $[110,111]$. Only recently, considerable efforts have been focused on understanding the genetic basis of autism and led to the identification of multiple chromosomal loci and epigenetic factors associated with autism heritability (for a review, [112]). Given the complex repertoire of symptoms characterising autistic syndrome, it has been proposed that defects in the development and functioning of multiple and relatively independent neural systems work together to generate the pathological phenotype. In particular, neural circuits underlying social and emotional behaviour, language processing, and higherorder cognition are considered natural candidates [113].

Converging results have pointed to an increased excitation/inhibition ratio in sensory, mnemonic, social, and emotional systems as a core mechanism underlying neurological and behavioural deficits observed in autistic patients [58]. Consistently, clinical studies showed that epilepsy displays a good percentage of comorbidity with autism [114]. An imbalance of neural circuits leading to a disproportionate high level of excitation could be due to increased glutamatergic transmission or suppressed GABAergic inhibition. The hypothesis that a reduction of inhibitory neurotransmission shared in common between many systems could be a key factor in the pathogenesis of autism is consistent with a large body of evidence [115]. Indeed, a significant reduction in protein levels of both isoforms of glutamic acid decarboxylase $[116,117]$ and GABA receptors [118-120] has been reported in autistic cerebral cortex. Linkage genetic studies uncovered that polymorphism, copy number, and epigenetic alterations in chromosomal regions containing GABA receptor subunit genes are associated with autistic phenotype [121-123].

On the cellular level, it has been shown that in a valproic acid rat model of autism, the amygdala is hyperreactive to electrical stimulation and displays enhanced synaptic plasticity as well as defective inhibitory transmission [124]. Moreover, a direct demonstration that inhibitory circuitries are activated atypically and are less synchronized in the brain of autistic people has been provided by studies of functional magnetic resonance imaging $[125,126]$.

Since autism is a developmental disorder, the imbalance in the ratio of excitation versus inhibition could result from abnormal processes during neural circuit maturation. Indeed, defects in synaptogenesis and synaptic refinement have been suggested to be a leading cause of autism, and mutations of genes that normally control the patterning of synaptic maturation of specific neuronal subpopulations have been shown to segregate with the pathological phenotype $[127,128]$. Among these genes, Dlx1 and Dlx2 encode transcription factors exerting a crucial role in the generation of GABAergic cortical interneurons and lie in a chromosomal region associated with autism susceptibility [129]. In accordance with the excitation/inhibition model, it has been proposed that pharmacological agents that reduce neural excitation, such as anticonvulsivants and benzodiazepines, could represent a suitable therapeutic treatment for autism [58]. At present, some evidence that anticonvulsivants could be effective in ameliorating autistic symptoms is available (e.g., $[130-132])$.

It should be pointed out, however, that the exact role of excitation/inhibition balance in autism is still debated. Indeed, an increased inhibitory synaptic transmission and a decreased glutamatergic excitation have been also reported in different transgenic mouse models of autism $[133,134]$.

\section{Concluding Remarks}

Altogether the results reviewed here show how dramatic can be the influence exerted by inhibitory transmission on brain plasticity. Not only are these findings crucial to our knowledge about the molecular mechanisms underlying the expression and regulation of plasticity processes, but they also have strong implications for the treatment of neurological disorders related to an aberrant development of GABAergic circuits. The possibility of rescuing a normal phenotype in animal models of these pathologies by manipulating levels of intracortical inhibition draws attention on the GABAergic system as an eligible candidate for the development of new therapeutic strategies.

\section{Acknowledgment}

The research was supported by a grant from Regione Toscana (Regional Health Research Program 2009) to Alessandro Sale and a grant from Fondazione Cassa di Risparmio di Pisa to Lamberto Maffei.

\section{References}

[1] N. Berardi, T. Pizzorusso, and L. Maffei, "Critical periods during sensory development," Current Opinion in Neurobiology, vol. 10, no. 1, pp. 138-145, 2000.

[2] T. K. Hensch, "Critical period regulation," Annual Review of Neuroscience, vol. 27, pp. 549-579, 2004.

[3] T. N. Wiesel and D. H. Hubel, "Single-cell responses in striate cortex of kittens deprived of vision in one eye," Journal of Neurophysiology, vol. 26, pp. 1003-1017, 1963.

[4] D. H. Hubel, T. N. Wiesel, and S. LeVay, "Plasticity of ocular dominance columns in monkey striate cortex," Philosophical Transactions of the Royal Society of London B, vol. 278, no. 961, pp. 377-409, 1977.

[5] C. J. Shatz and M. P. Stryker, "Ocular dominance in layer IV of the cat's visual cortex and the effects of monocular deprivation," Journal of Physiology, vol. 281, pp. 267-283, 1978. 
[6] S. LeVay, T. N. Wiesel, and D. H. Hubel, "The development of ocular dominance columns in normal and visually deprived monkeys," Journal of Comparative Neurology, vol. 191, no. 1, pp. 1-51, 1980.

[7] A. Antonini and M. P. Stryker, "Rapid remodeling of axonal arbors in the visual cortex," Science, vol. 260, no. 5115, pp. 1819-1821, 1993.

[8] J. T. Trachtenberg and M. P. Stryker, "Rapid anatomical plasticity of horizontal connections in the developing visual cortex," Journal of Neuroscience, vol. 21, no. 10, pp. 3476 3482, 2001.

[9] N. Berardi, T. Pizzorusso, G. M. Ratto, and L. Maffei, "Molecular basis of plasticity in the visual cortex," Trends in Neurosciences, vol. 26, no. 7, pp. 369-378, 2003.

[10] D. Tropea, A. van Wart, and M. Sur, "Molecular mechanisms of experience-dependent plasticity in visual cortex," Philosophical Transactions of the Royal Society B, vol. 364, no. 1515, pp. 341-355, 2009.

[11] F. Fernandez and C. C. Garner, "Over-inhibition: a model for developmental intellectual disability," Trends in Neurosciences, vol. 30, no. 10, pp. 497-503, 2007.

[12] M. Spolidoro, A. Sale, N. Berardi, and L. Maffei, "Plasticity in the adult brain: lessons from the visual system," Experimental Brain Research, vol. 192, no. 3, pp. 335-341, 2009.

[13] T. K. Hensch, M. Fagiolini, N. Mataga, M. P. Stryker, S. Baekkeskov, and S. F. Kash, "Local GABA circuit control of experience-dependent plasticity in developing visual cortex," Science, vol. 282, no. 5393, pp. 1504-1508, 1998.

[14] Z. J. Huang, A. Kirkwood, T. Pizzorusso et al., "BDNF regulates the maturation of inhibition and the critical period of plasticity in mouse visual cortex," Cell, vol. 98, no. 6, pp. 739-755, 1999.

[15] L. Cancedda, E. Putignano, A. Sale, A. Viegi, N. Berardi, and L. Maffei, "Acceleration of visual system development by environmental enrichment," Journal of Neuroscience, vol. 24, no. 20, pp. 4840-4848, 2004.

[16] G. di Cristo, B. Chattopadhyaya, S. J. Kuhlman et al., "Activity-dependent PSA expression regulates inhibitory maturation and onset of critical period plasticity," Nature Neuroscience, vol. 10, no. 12, pp. 1569-1577, 2007.

[17] S. Sugiyama, A. A. di Nardo, S. Aizawa et al., "Experiencedependent transfer of ot $\times 2$ Homeoprotein into the visual cortex activates postnatal plasticity," Cell, vol. 134, no. 3, pp. 508-520, 2008.

[18] A. Harauzov, M. Spolidoro, G. DiCristo et al., "Reducing intracortical inhibition in the adult visual cortex promotes ocular dominance plasticity," Journal of Neuroscience, vol. 30, no. 1, pp. 361-371, 2010.

[19] A. Kirkwood and M. F. Bear, "Hebbian synapses in visual cortex," Journal of Neuroscience, vol. 14, no. 3, pp. 1634-1645, 1994.

[20] N. Mataga, N. Nagai, and T. K. Hensch, "Permissive proteolytic activity for visual cortical plasticity," Proceedings of the National Academy of Sciences of the United States of America, vol. 99, no. 11, pp. 7717-7721, 2002.

[21] S. Oray, A. Majewska, and M. Sur, "Dendritic spine dynamics are regulated by monocular deprivation and extracellular matrix degradation," Neuron, vol. 44, no. 6, pp. 1021-1030, 2004.

[22] T. Pizzorusso, P. Medini, N. Berardi, S. Chierzi, J. W. Fawcett, and L. Maffei, "Reactivation of ocular dominance plasticity in the adult visual cortex," Science, vol. 298, no. 5596, pp. 1248 1251, 2002.
[23] A. W. McGee, Y. Yang, Q. S. Fischer, N. W. Daw, and S. H. Strittmatter, "Neuroscience: experience-driven plasticity of visual cortex limited by myelin and nogo receptor," Science, vol. 309, no. 5744, pp. 2222-2226, 2005.

[24] A. Dityatev, M. Schachner, and P. Sonderegger, "The dual role of the extracellular matrix in synaptic plasticity and homeostasis," Nature Reviews Neuroscience, vol. 11, no. 11, pp. 735-746, 2010.

[25] L. Baroncelli, A. Sale, A. Viegi et al., "Experience-dependent reactivation of ocular dominance plasticity in the adult visual cortex," Experimental Neurology, vol. 226, no. 1, pp. 100-109, 2010.

[26] J. F. Maya Vetencourt, A. Sale, A. Viegi et al., "The antidepressant fluoxetine restores plasticity in the adult visual cortex," Science, vol. 320, no. 5874, pp. 385-388, 2008.

[27] H. Morishita, J. M. Miwa, N. Heintz, and T. K. Hensch, "Lynx1, a cholinergic brake, limits plasticity in adult visual cortex," Science, vol. 330, no. 6008, pp. 1238-1240, 2010.

[28] H. Y. He, W. Hodos, and E. M. Quinlan, "Visual deprivation reactivates rapid ocular dominance plasticity in adult visual cortex," Journal of Neuroscience, vol. 26, no. 11, pp. 29512955, 2006.

[29] S. Huang, Y. Gu, E. M. Quinlan, and A. Kirkwood, "A refractory period for rejuvenating GABAergic synaptic transmission and ocular dominance plasticity with dark exposure," Journal of Neuroscience, vol. 30, no. 49, pp. $16636-$ 16642, 2010.

[30] B. Jiang, S. Huang, R. de Pasquale et al., "The maturation of GABAergic transmission in visual cortex requires endocannabinoid-mediated LTD of inhibitory inputs during a critical period," Neuron, vol. 66, no. 2, pp. 248-259, 2010.

[31] M. S. Brainard and E. I. Knudsen, "Sensitive periods for visual calibration of the auditory space map in the barn owl optic tectum," Journal of Neuroscience, vol. 18, no. 10, pp. 3929-3942, 1998.

[32] E. I. Knudsen and P. F. Knudsen, "Sensitive and critical periods for visual calibration of sound localization by barn owls," Journal of Neuroscience, vol. 10, no. 1, pp. 222-232, 1990.

[33] W. Zheng and E. I. Knudsen, "Functional selection of adaptive auditory space map by GABA(a)-mediated inhibition," Science, vol. 284, no. 5416, pp. 962-965, 1999.

[34] L. I. Zhang, S. Bao, and M. M. Merzenich, "Persistent and specific influences of early acoustic environments on primary auditory cortex," Nature Neuroscience, vol. 4, no. 11, pp. 1123-1130, 2001.

[35] X. Zhou, R. Panizzutti, É. de Villers-Sidani, C. Madeira, and M. M. Merzenich, "Natural restoration of critical period plasticity in the juvenile and adult primary auditory cortex," Journal of Neuroscience, vol. 31, no. 15, pp. 5625-5634, 2011.

[36] J. M. Holmes and M. P. Clarke, "Amblyopia," The Lancet, vol. 367, no. 9519, pp. 1343-1351, 2006.

[37] T. L. Lewis and D. Maurer, "Multiple sensitive periods in human visual development: evidence from visually deprived children," Developmental Psychobiology, vol. 46, no. 3, pp. 163-183, 2005.

[38] D. M. Levi and R. W. Li, "Improving the performance of the amblyopic visual system," Philosophical Transactions of the Royal Society B, vol. 364, no. 1515, pp. 399-407, 2009.

[39] G. R. Barnes, R. F. Hess, S. O. Dumoulin, R. L. Achtman, and G. B. Pike, "The cortical deficit in humans with strabismic amblyopia," Journal of Physiology, vol. 533, no. 1, pp. 281297, 2001. 
[40] R. F. Hess, “Amblyopia: site unseen," Clinical and Experimental Optometry, vol. 84, pp. 321-336, 2001.

[41] X. Li, S. O. Dumoulin, B. Mansouri, and R. F. Hess, "Cortical deficits in human amblyopia: their regional distribution and their relationship to the contrast detection deficit," Investigative Ophthalmology and Visual Science, vol. 48, no. 4, pp. 1575-1591, 2007.

[42] C. Wu and D. G. Hunter, "Amblyopia: diagnostic and therapeutic options," American Journal of Ophthalmology, vol. 141, no. 1, pp. 175-184, 2006.

[43] U. Polat, "Restoration of underdeveloped cortical functions: evidence from treatment of adult amblyopia," Restorative Neurology and Neuroscience, vol. 26, no. 4-5, pp. 413-424, 2008.

[44] U. Polat, "Functional architecture of long-range perceptual interactions," Spatial Vision, vol. 12, no. 2, pp. 143-162, 1999.

[45] D. M. Levi, S. Hariharan, and S. A. Klein, "Suppressive and facilitatory spatial interactions in amblyopic vision," Vision Research, vol. 42, no. 11, pp. 1379-1394, 2002.

[46] U. Polat, T. Ma-Naim, M. Belkin, and D. Sagi, "Improving vision in adult amblyopia by perceptual learning," Proceedings of the National Academy of Sciences of the United States of America, vol. 101, no. 17, pp. 6692-6697, 2004.

[47] U. Polat, Y. Bonneh, T. Ma-Naim, M. Belkin, and D. Sagi, "Spatial interactions in amblyopia: effects of stimulus parameters and amblyopia type," Vision Research, vol. 45, no. 11, pp. 1471-1479, 2005.

[48] E. H. Wong, D. M. Levi, and P. V. McGraw, "Spatial interactions reveal inhibitory cortical networks in human amblyopia," Vision Research, vol. 45, no. 21, pp. 2810-2819, 2005.

[49] B. Timney, "The effects of early and late monocular deprivation on binocular depth perception in cats," Brain Research, vol. 283, no. 2-3, pp. 235-243, 1983.

[50] L. Kiorpes, D. C. Kiper, L. P. O'Keefe, J. R. Cavanaugh, and J. A. Movshon, "Neuronal correlates of amblyopia in the visual cortex of macaque monkeys with experimental strabismus and anisometropia," Journal of Neuroscience, vol. 18, no. 16, pp. 6411-6424, 1998.

[51] G. T. Prusky and R. M. Douglas, "Developmental plasticity of mouse visual acuity," European Journal of Neuroscience, vol. 17, no. 1, pp. 167-173, 2003.

[52] F. H. Duffy, J. L. Burchfiel, J. L. Conway, and S. R. Snodgrass, "Bicuculline reversal of deprivation amblyopia in the cat," Nature, vol. 260, no. 5548, pp. 256-257, 1976.

[53] J. L. Burchfiel and F. H. Duffy, "Role of intracortical inhibition in deprivation amblyopia: reversal by microiontophoretic bicuculline," Brain Research, vol. 206, no. 2, pp. 479-484, 1981.

[54] D. Bavelier, D. M. Levi, R. W. Li, Y. Dan, and T. K. Hensch, "Removing brakes on adult brain plasticity: from molecular to behavioral interventions," Journal of Neuroscience, vol. 30, no. 45, pp. 14964-14971, 2010.

[55] A. Sale, N. Berardi, M. Spolidoro et al., "GABAergic inhibition in visual cortical plasticity," Frontiers in Cellular Neuroscience, vol. 4, no. 10, 2010.

[56] A. Sale, J. F. Maya Vetencourt, P. Medini et al., "Environmental enrichment in adulthood promotes amblyopia recovery through a reduction of intracortical inhibition," Nature Neuroscience, vol. 10, no. 6, pp. 679-681, 2007.

[57] L. Baroncelli, C. Braschi, M. Spolidoro, T. Begenisic, A. Sale, and L. Maffei, "Nurturing brain plasticity: impact of environmental enrichment," Cell Death \& Differentiation, vol. 17, no. 7, pp. 1092-1103, 2010.
[58] J. L. Rubenstein and M. M. Merzenich, "Model of autism: increased ratio of excitation/inhibition in key neural systems," Genes, Brain \& Behavior, vol. 2, no. 5, pp. 255-267, 2003.

[59] B. Hagberg, J. Aicardi, K. Dias, and O. Ramos, "A progressive syndrome of autism, dementia, ataxia, and loss of purposeful hand use in girls: Rett's syndrome. report of 35 cases," Annals of Neurology, vol. 14, no. 4, pp. 471-479, 1983.

[60] R. E. Amir, I. B. van den Veyver, M. Wan, C. Q. Tran, U. Francke, and H. Y. Zoghbi, "Rett syndrome is caused by mutations in X-linked MECP2, encoding methyl- CpGbinding protein 2," Nature Genetics, vol. 23, no. 2, pp. 185188, 1999.

[61] M. Chahrour, Y. J. Sung, C. Shaw et al., "MeCP2, a key contributor to neurological disease, activates and represses transcription," Science, vol. 320, no. 5880, pp. 1224-1229, 2008.

[62] J. I. Young, E. P. Hong, J. C. Castle et al., "Regulation of RNA splicing by the methylation-dependent transcriptional repressor methyl-CpG binding protein 2," Proceedings of the National Academy of Sciences of the United States of America, vol. 102, no. 49, pp. 17551-17558, 2005.

[63] R. Z. Chen, S. Akbarian, M. Tudor, and R. Jaenisch, "Deficiency of methyl-CpG binding protein-2 in CNS neurons results in a rett-like phenotype in mice," Nature Genetics, vol. 27, no. 3, pp. 327-331, 2001.

[64] J. Guy, B. Hendrich, M. Holmes, J. E. Martin, and A. Bird, "A mouse Mecp2-null mutation causes neurological symptoms that mimic Rett syndrome," Nature Genetics, vol. 27, no. 3, pp. 322-326, 2001.

[65] P. Moretti, J. A. Bouwknecht, R. Teague, R. Paylor, and H. Y. Zoghbi, "Abnormalities of social interactions and homecage behavior in a mouse model of Rett syndrome," Human Molecular Genetics, vol. 14, no. 2, pp. 205-220, 2005.

[66] N. A. Stearns, L. R. Schaevitz, H. Bowling, N. Nag, U. V. Berger, and J. Berger-Sweeney, "Behavioral and anatomical abnormalities in Mecp2 mutant mice: a model for Rett syndrome," Neuroscience, vol. 146, no. 3, pp. 907-921, 2007.

[67] V. S. Dani, Q. Chang, A. Maffei, G. G. Turrigiano, R. Jaenisch, and S. B. Nelson, "Reduced cortical activity due to a shift in the balance between excitation and inhibition in a mouse model of Rett syndrome," Proceedings of the National Academy of Sciences of the United States of America, vol. 102, no. 35, pp. 12560-12565, 2005.

[68] Y. Asaka, D. G. Jugloff, L. Zhang, J. H. Eubanks, and R. M. Fitzsimonds, "Hippocampal synaptic plasticity is impaired in the Mecp2-null mouse model of Rett syndrome," Neurobiology of Disease, vol. 21, no. 1, pp. 217-227, 2006.

[69] P. Moretti, J. M. Levenson, F. Battaglia et al., "Learning and memory and synaptic plasticity are impaired in a mouse model of Rett syndrome," Journal of Neuroscience, vol. 26, no. 1, pp. 319-327, 2006.

[70] M. E. Blue, S. Naidu, and M. V. Johnston, "Altered development of glutamate and GABA receptors in the basal ganglia of girls with Rett syndrome," Experimental Neurology, vol. 156, no. 2, pp. 345-352, 1999.

[71] H.-T. Chao, H. Chen, R. C. Samaco et al., "Dysfunction in GABA signalling mediates autism-like stereotypies and Rett syndrome phenotypes," Nature, vol. 468, no. 7321, pp. 263269, 2010.

[72] W. G. Chen, Q. Chang, Y. Lin et al., "Derepression of BDNF transcription involves calcium-dependent phosphorylation of MeCP2," Science, vol. 302, no. 5646, pp. 885-889, 2003. 
[73] Q. Chang, G. Khare, V. Dani, S. Nelson, and R. Jaenisch, “The disease progression of Mecp2 mutant mice is affected by the level of BDNF expression," Neuron, vol. 49, no. 3, pp. 341348, 2006.

[74] D. D. Kline, M. Ogier, D. L. Kunze, and D. M. Katz, "Exogenous brain-derived neurotrophic factor rescues synaptic dysfunction in Mecp2-null mice," Journal of Neuroscience, vol. 30, no. 15, pp. 5303-5310, 2010.

[75] G. Lonetti, A. Angelucci, L. Morando, E. M. Boggio, M. Giustetto, and T. Pizzorusso, "Early environmental enrichment moderates the behavioral and synaptic phenotype of MeCP2 null mice," Biological Psychiatry, vol. 67, no. 7, pp. 657-665, 2010.

[76] J. Lejeune, "The 21 Trisomy_current stage of chromosomal research," Progress in Medical Genetics, vol. 23, pp. 144-177, 1964.

[77] L. Nadel, “Down's syndrome: a genetic disorder in biobehavioral perspective," Genes, Brain and Behavior, vol. 2, no. 3, pp. 156-166, 2003.

[78] B. F. Pennington, J. Moon, J. Edgin, J. Stedron, and L. Nadel, "The neuropsychology of Down syndrome: evidence for hippocampal dysfunction," Child Development, vol. 74, no. 1, pp. 75-93, 2003.

[79] K. Gardiner, A. Fortna, L. Bechtel, and M. T. Davisson, "Mouse models of Down syndrome: how useful can they be? Comparison of the gene content of human chromosome 21 with orthologous mouse genomic regions," Gene, vol. 318, no. 1-2, pp. 137-147, 2003.

[80] Z. Sérégaza, P. L. Roubertoux, M. Jamon, and B. SoumireuMourat, "Mouse models of cognitive disorders in trisomy 21: a review," Behavior Genetics, vol. 36, no. 3, pp. 387-404, 2006.

[81] M. T. Davisson, C. Schmidt, and E. C. Akeson, "Segmental trisomy of murine chromosome 16: a new model system for studying Down syndrome," Progress in Clinical and Biological Research, vol. 360, pp. 263-280, 1990.

[82] R. M. Escorihuela, A. Fernández-Teruel, I. F. Vallina et al., "A behavioral assessment of Ts65Dn mice: a putative Down syndrome model," Neuroscience Letters, vol. 199, no. 2, pp. 143-146, 1995.

[83] D. M. Holtzman, D. Santucci, J. Kilbridge et al., "Developmental abnormalities and age-related neurodegeneration in a mouse model of down syndrome," Proceedings of the National Academy of Sciences of the United States of America, vol. 93, no. 23, pp. 13333-13338, 1996.

[84] R. M. Escorihuela, I. F. Vallina, C. Martínez-Cué et al., "Impaired short- and long-term memory in Ts65Dn mice, a model for down syndrome," Neuroscience Letters, vol. 247, no. 2-3, pp. 171-174, 1998.

[85] J. J. Scott-McKean, B. Chang, R. E. Hurd et al., "The mouse model of Down syndrome Ts65Dn presents visual deficits as assessed by pattern visual evoked potentials," Investigative Ophthalmology \& Visual Science, vol. 51, no. 6, pp. 33003308, 2010.

[86] A. M. Insausti, M. Megías, D. Crespo et al., "Hippocampal volume and neuronal number in Ts65Dn mice: a murine model of D own syndrome," Neuroscience Letters, vol. 253, no. 3, pp. 175-178, 1998.

[87] M. A. Kurt, M. I. Kafa, M. Dierssen, and D. C. Davies, "Deficits of neuronal density in CA1 and synaptic density in the dentate gyrus, CA3 and CA1, in a mouse model of Down syndrome," Brain Research, vol. 1022, no. 1-2, pp. 101-109, 2004.
[88] R. J. Roper, L. L. Baxter, N. G. Saran, D. K. Klinedinst, P. A. Beachy, and R. H. Reeves, "Defective cerebellar response to mitogenic hedgehog signaling in Down syndrome mice," Proceedings of the National Academy of Sciences of the United States of America, vol. 103, no. 5, pp. 1452-1456, 2006.

[89] S. Clark, J. Schwalbe, M. R. Stasko, P. J. Yarowsky, and A. C. S. Costa, "Fluoxetine rescues deficient neurogenesis in hippocampus of the Ts65Dn mouse model for Down syndrome," Experimental Neurology, vol. 200, no. 1, pp. 256261, 2006.

[90] S. Guidi, P. Bonasoni, C. Ceccarelli et al., "Neurogenesis impairment and increased cell death reduce total neuron number in the hippocampal region of fetuses with Down syndrome," Brain Pathology, vol. 18, no. 2, pp. 180-197, 2008.

[91] M. Dierssen, R. Benavides-Piccione, C. Martínez-Cué et al., "Alterations of neocortical pyramidal cell phenotype in the Ts65Dn mouse model of Down syndrome: effects of environmental enrichment," Cerebral Cortex, vol. 13, no. 7, pp. 758-764, 2003.

[92] P. V. Belichenko, E. Masliah, A. M. Kleschevnikov et al., "Synaptic structural abnormalities in the Ts65Dn mouse model of Down syndrome," Journal of Comparative Neurology, vol. 480, no. 3, pp. 281-298, 2004.

[93] D. Necchi, S. Lomoio, and E. Scherini, "Axonal abnormalities in cerebellar purkinje cells of the Ts65Dn mouse," Brain Research, vol. 1238, pp. 181-188, 2008.

[94] J. D. Cooper, A. Salehi, J. D. Delcroix et al., "Failed retrograde transport of NGF in a mouse model of Down's syndrome: reversal of cholinergic neurodegenerative phenotypes following NGF infusion," Proceedings of the National Academy of Sciences of the United States of America, vol. 98, no. 18, pp. 10439-10444, 2001.

[95] A. Salehi, J. D. Delcroix, P. V. Belichenko et al., "Increased App expression in a mouse model of Down's syndrome disrupts NGF transport and causes cholinergic neuron degeneration," Neuron, vol. 51, no. 1, pp. 29-42, 2006.

[96] O. Isacson, H. Seo, L. Lin, D. Albeck, and A. C. Granholm, "Alzheimer's disease and Down's syndrome: roles of APP, trophic factors and ACh," Trends in Neurosciences, vol. 25, no. 2, pp. 79-84, 2002.

[97] I. T. Lott and E. Head, "Alzheimer disease and down syndrome: factors in pathogenesis," Neurobiology of Aging, vol. 26, no. 3, pp. 383-389, 2005.

[98] R. J. Siarey, E. J. Carlson, C. J. Epstein, A. Balbo, S. I. Rapoport, and Z. Galdzicki, "Increased synaptic depression in the Ts65Dn mouse, a model for mental retardation in Down syndrome," Neuropharmacology, vol. 38, no. 12, pp. 1917-1920, 1999.

[99] A. M. Kleschevnicov, P. V. Belichenko, A. J. Villar, C. J. Epstein, R. C. Malenka, and W. C. Mobley, "Hippocampal long-term potentiation suppressed by increased inhibition in the Ts65Dn mouse, a genetic model of Down syndrome," Journal of Neuroscience, vol. 24, no. 37, pp. 8153-8160, 2004.

[100] F. Fernandez, W. Morishita, E. Zuniga et al., "Pharmacotherapy for cognitive impairment in a mouse model of Down syndrome," Nature Neuroscience, vol. 10, no. 4, pp. 411-413, 2007.

[101] P. V. Belichenko, A. M. Kleschevnikov, E. Masliah et al., "Excitatory-inhibitory relationship in the fascia dentata in the Ts65Dn mouse model of Down syndrome," Journal of Comparative Neurology, vol. 512, no. 4, pp. 453-466, 2009. 
[102] D. Pórez-Cremades, S. Hernández, J. M. Blasco-Ibáñez, C. Crespo, J. Nacher, and E. Varea, "Alteration of inhibitory circuits in the somatosensory cortex of Ts65Dn mice, a model for Down's syndrome," Journal of Neural Transmission, vol. 117, no. 4, pp. 445-455, 2010.

[103] L. Chakrabarti, T. K. Best, N. P. Cramer et al., "Olig1 and Olig2 triplication causes developmental brain defects in Down syndrome," Nature Neuroscience, vol. 13, no. 8, pp. 927-934, 2010.

[104] A. Sale, N. Berardi, and L. Maffei, "Enrich the environment to empower the brain," Trends in Neurosciences, vol. 32, no. 4, pp. 233-239, 2009.

[105] C. Martínez-Cué, C. Baamonde, M. Lumbreras et al., "Differential effects of environmental enrichment on behavior and learning of male and female Ts65Dn mice, a model for Down syndrome," Behavioural Brain Research, vol. 134, no. 1-2, pp. 185-200, 2002.

[106] M. Rutter, D. Greenfeld, and L. Lockyer, "A five to fifteen year follow-up study of infantile psychosis. II. social and behavioural outcome," British Journal of Psychiatry, vol. 113, no. 504, pp. 1183-1199, 1967.

[107] L. Lockyer and M. Rutter, "A five- to fifteen-year follow-up study of infantile psychosis. IV. patterns of cognitive ability," The British Journal of Social and Clinical Psychology, vol. 9, no. 2, pp. 152-163, 1970.

[108] S. Chakrabarti and E. Fombonne, "Pervasive developmental disorders in preschool children," Journal of the American Medical Association, vol. 285, no. 24, pp. 3093-3099, 2001.

[109] A. C. Stanfield, A. M. McIntosh, M. D. Spencer, R. Philip, S. Gaur, and S. M. Lawrie, "Towards a neuroanatomy of autism: asystematic review and meta-analysis of structural magnetic resonance imaging studies," European Psychiatry, vol. 23, no. 4, pp. 289-299, 2008.

[110] S. Folstein and M. Rutter, "Genetic influences and infantile autism," Nature, vol. 265, no. 5596, pp. 726-728, 1977.

[111] A. Bailey, A. Le Couteur, I. Gottesman et al., "Autism as a strongly genetic disorder: evidence from a British twin study," Psychological Medicine, vol. 25, no. 1, pp. 63-77, 1995.

[112] B. S. Abrahams and D. H. Geschwind, "Advances in autism genetics: on the threshold of a new neurobiology," Nature Reviews Genetics, vol. 9, no. 5, pp. 341-355, 2008.

[113] S. O. Moldin, J. L. Rubenstein, and S. E. Hyman, "Can autism speak to neuroscience?" Journal of Neuroscience, vol. 26, no. 26, pp. 6893-6896, 2006.

[114] C. Gillberg and E. Billstedt, "Autism and asperger syndrome: coexistence with other clinical disorders," Acta Psychiatrica Scandinavica, vol. 102, no. 5, pp. 321-330, 2000.

[115] J. P. Hussman, "Suppressed gabaergic inhibition as a common factor in suspected etiologies of autism," Journal of Autism and Developmental Disorders, vol. 31, no. 2, pp. 247248, 2001.

[116] S. H. Fatemi, A. R. Halt, J. M. Stary, R. Kanodia, S. C. Schulz, and G. R. Realmuto, "Glutamic acid decarboxylase 65 and $67 \mathrm{kDa}$ proteins are reduced in autistic parietal and cerebellar cortices," Biological Psychiatry, vol. 52, no. 8, pp. 805-810, 2002.

[117] J. Yip, J. J. Soghomonian, and G. J. Blatt, "Decreased GAD67 mRNA levels in cerebellar purkinje cells in autism: pathophysiological implications," Acta Neuropathologica, vol. 113 , no. 5, pp. 559-568, 2007.
[118] S. H. Fatemi, T. J. Reutiman, T. D. Folsom et al., "mRNA and protein levels for GABAAalpha4, alpha5, beta1 and GABABR1 receptors are altered in brains from subjects with autism," Journal of Autism and Developmental Disorders, vol. 40, no. 6, pp. 743-750, 2010.

[119] A. L. Oblak, T. T. Gibbs, and G. J. Blatt, "Decreased GABA(B) receptors in the cingulate cortex and fusiform gyrus in autism," Journal of Neurochemistry, vol. 114, no. 5, pp. 1414$1423,2010$.

[120] A. L. Oblak, T. T. Gibbs, and G. J. Blatt, "Reduced GABAA receptors and benzodiazepine binding sites in the posterior cingulate cortex and fusiform gyrus in autism," Brain Research, vol. 1380, pp. 218-228, 2011.

[121] M. M. Menold, Y. Shao, C. M. Wolpert et al., "Association analysis of chromosome 15 GABAA receptor subunit genes in autistic disorder," Journal of Neurogenetics, vol. 15, no. 3-4, pp. 245-259, 2001.

[122] J. D. Buxbaum, J. M. Silverman, C. J. Smith et al., "Association between a GABRB3 polymorphism and autism," Molecular Psychiatry, vol. 7, no. 3, pp. 311-316, 2002.

[123] A. Hogart, R. P. Nagarajan, K. A. Patzel, D. H. Yasui, and J. M. LaSalle, "15q11-13 GABAA receptor genes are normally biallelically expressed in brain yet are subject to epigenetic dysregulation in autism-spectrum disorders," Human Molecular Genetics, vol. 16, no. 6, pp. 691-703, 2007.

[124] K. Markram, T. Rinaldi, D. L. Mendola, C. Sandi, and H. Markram, "Abnormal fear conditioning and amygdala processing in an animal model of autism," Neuropsychopharmacology, vol. 33, no. 4, pp. 901-912, 2008.

[125] N. Schmitz, K. Rubia, E. Daly, A. Smith, S. Williams, and D. G. M. Murphy, "Neural correlates of executive function in autistic spectrum disorders," Biological Psychiatry, vol. 59, no. 1, pp. 7-16, 2006.

[126] R. K. Kana, T. A. Keller, N. J. Minshew, and M. A. Just, "Inhibitory control in high-functioning autism: decreased activation and underconnectivity in inhibition networks," Biological Psychiatry, vol. 62, no. 3, pp. 198-206, 2007.

[127] F. Polleux and J. M. Lauder, "Toward a developmental neurobiology of autism," Mental Retardation and Developmental Disabilities Research Reviews, vol. 10, no. 4, pp. 303-317, 2004.

[128] C. L. Gatto and K. Broadie, "Genetic controls balancing excitatory and inhibitory synaptogenesis in neurodevelopmental disorder models," Frontiers in Synaptic Neuroscience, vol. 2, no. 4,2010

[129] X. Liu, N. Novosedlik, A. Wang et al., "The DLX1and DLX2 genes and susceptibility to autism spectrum disorders," European Journal of Human Genetics, vol. 17, no. 2, pp. 228235, 2009.

[130] K. M. Belsito, P. A. Law, K. S. Kirk, R. J. Landa, and A. W. Zimmerman, "Lamotrigine therapy for autistic disorder: a randomized, double-blind, placebo-controlled trial," Journal of Autism and Developmental Disorders, vol. 31, no. 2, pp. 175-181, 2001.

[131] A. di Martino and R. F. Tuchman, "Antiepileptic drugs: affective use in autism spectrum disorders," Pediatric Neurology, vol. 25, no. 3, pp. 199-207, 2001.

[132] L. West, J. Waldrop, and S. Brunssen, "Pharmacologic treatment for the core deficits and associated symptoms of autism in children," Journal of Pediatric Health Care, vol. 23, no. 2, pp. 75-89, 2009. 
[133] K. Tabuchi, J. Blundell, M. R. Etherton et al., "A neuroligin-3 mutation implicated in autism increases inhibitory synaptic transmission in mice," Science, vol. 318, no. 5847, pp. 71-76, 2007.

[134] J. Blundell, C. A. Blaiss, M. R. Etherton et al., "Neuroligin1 deletion results in impaired spatial memory and increased repetitive behavior," Journal of Neuroscience, vol. 30, no. 6, pp. 2115-2129, 2010. 

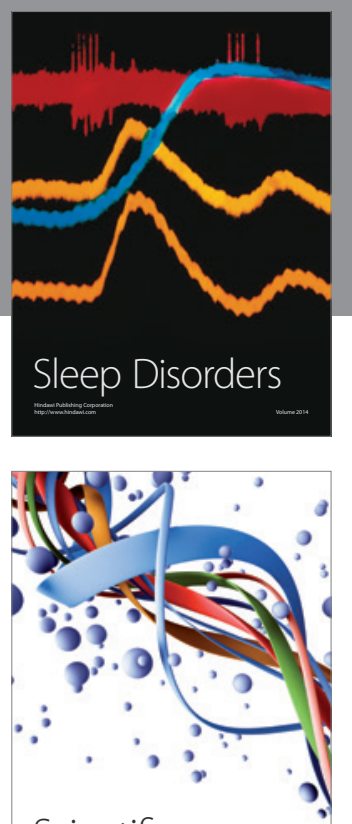

Scientifica
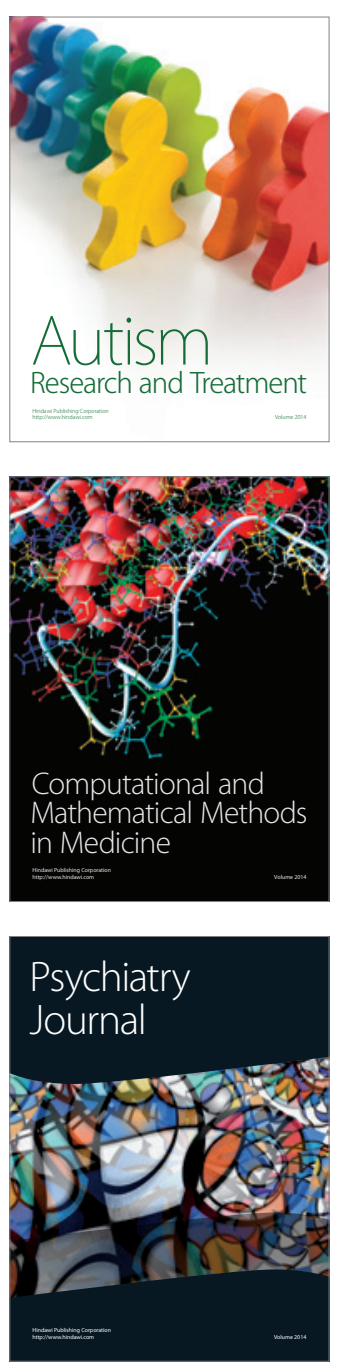
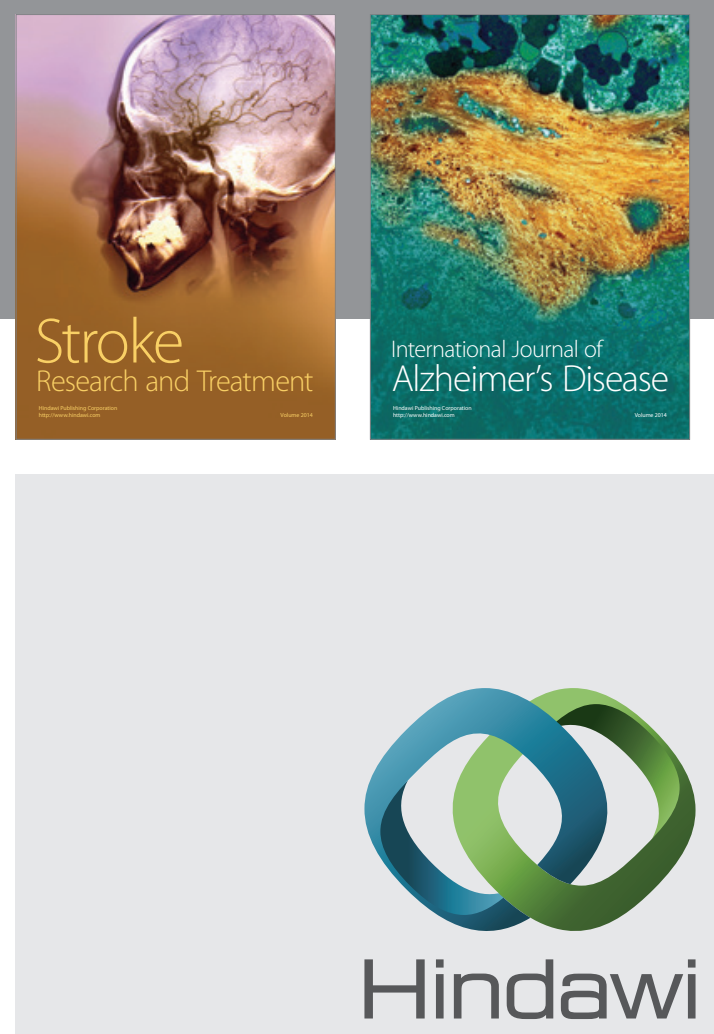

Submit your manuscripts at

http://www.hindawi.com
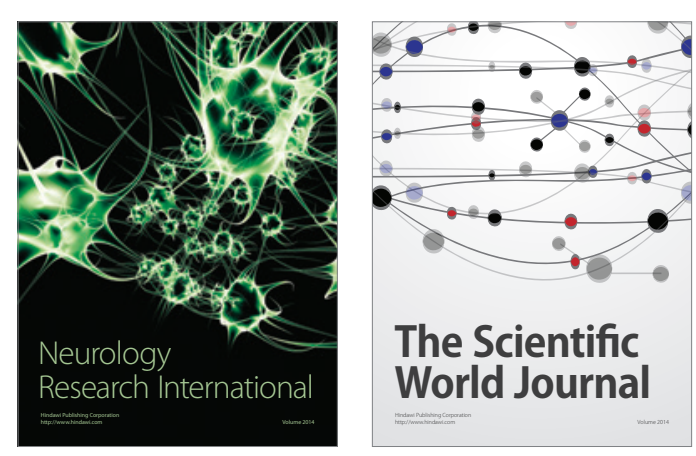

The Scientific World Journal

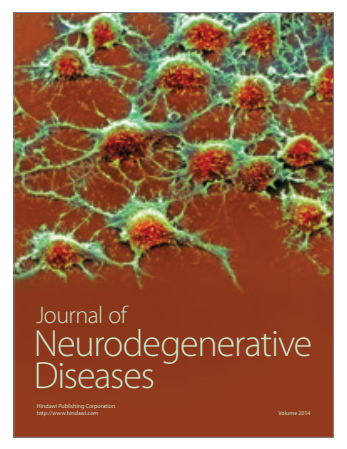

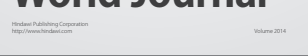

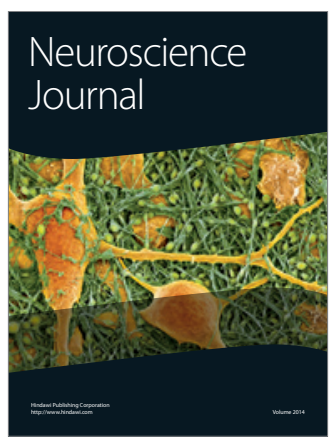

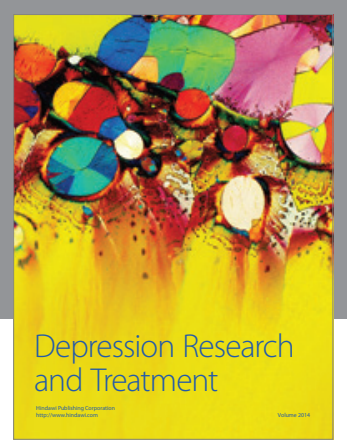
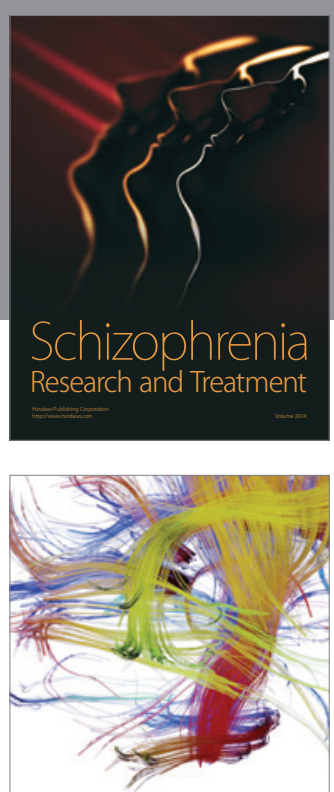

Brain Science

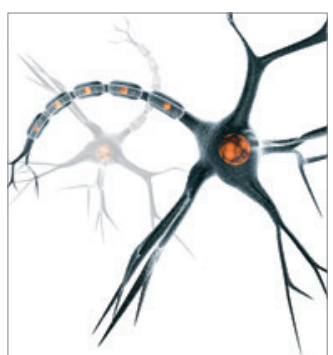

Neural Plasticity
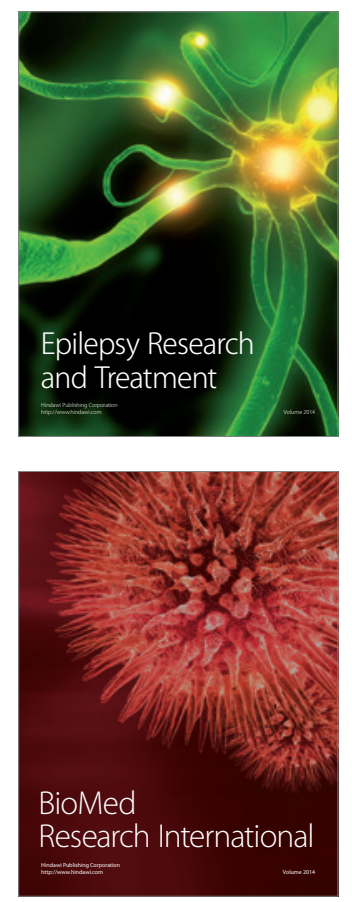

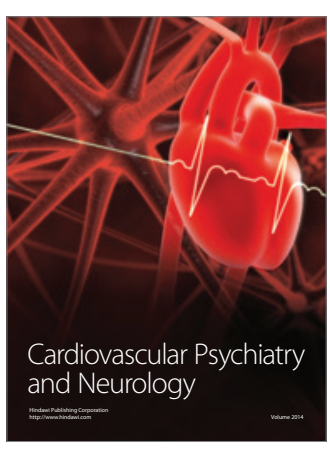

Parkinson's

Disease
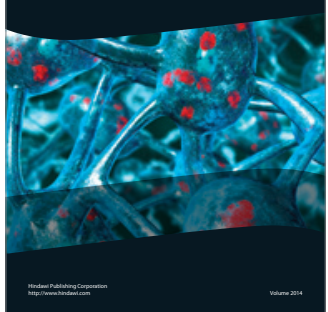